\title{
Hippocratean Squaring Of Lunes, Semicircle and Circle
}

\author{
R. D. Sarva Jagannadha Reddy \\ 19-9-73/D3, Sri Jayalakshmi Colony, S.T.V. Nagar, Tirupati- 517 501, A.P., India
}

\begin{abstract}
Hippocrates has squared lunes, circle and a semicircle. He is the first man and a last man. $S$. Ramanujan is the second mathematician who has squared a circle upto a few decimals of $\pi$ equal to $3.1415926 \ldots$ The squaring of curvature entities implies that lune, circle are finite entities having a finite magnitude to be represented by a finite number.
\end{abstract}

Keywords: Squaring, lune, circle, Hippocrates, S. Ramanujan, $\pi$, algebraic number.

\section{Introduction}

Hippocrates of Chios was a Greek mathematician, geometer and astronomer, who lived from 470 until 410 BC. He wrote a systematically organized geometry text book Stoicheia Elements. It is the first book. And hence he is called the Founding Father of Mathematics. This book was the basis for Euclid's Elements.

In his days the $\pi$ value was 3 of the Holy Bible. He is famous for squaring of lunes. The lunes are called Hippocratic lunes, or the lune of Hippocrates, which was part of a research project on the calculation of the area of a circle, referred to as the 'quadrature of the circle'. What is a lune ? It is the area present between two intersecting circles. It is based on the theorem that the areas of two circles have the same ratio as the squares of their radii. Simplicius.

His work is written by Eudemus of Rhodes (335 BC) with elaborate proofs and has been preserved by

Some believe he has not squared a circle. This view has become very strong with the number $3.1415926 \ldots$ a polygon's value attributed to circle, arrived at, from the Exhaustion method (EM) prevailing before Archimedes (240 BC) of Syracuse, Greece, and refined it by him, hence the EM is also known as Archimedean method. This number 3.1415926... has become much stronger as $\pi$ value, and has been dissociated from circle-polygon composite construction, with the introduction of infinite series of Madhavan (1450) of South India, and independently by later mathematicians John Wallis (1660) of England, James Gregory (1660) of Scotland.

With the progressive gaining of the importance of $3.1415926 \ldots$ as $\pi$ value from infinite series, the work of 'squaring of circle' of Hippocrates has gone into oblivion. When the prevailing situation is so, in the mean time, a great mathematician Leonhard Euler (1707-1783) of Switzerland has come. His record-setting output is about 530 books and articles during his lifetime, and many more manuscripts are left to posterity. He had created an interesting formula $\mathrm{e}^{\mathrm{i} \pi}+1=0$ and based on his formula, Carl Louis Ferdinand Lindemann (1852-1939) of Germany proved in 1882 that $\pi$ was a type of nonrational number called a transcendental number. (It means, it is one that is not the root of a polynomial equation with rational coefficients. Another way of saying this is that it is a number that cannot be expressed as a combination of the four basic arithmetic operations and root extraction. In other words, it is a number that cannot be expressed algebraically). Interestingly, the term transcendental number is introduced by Euler.

When all these happened, naturally, the work on the Squaring of circle by Hippocrates was almost buried permanently.

This author with his discovery in March 1998 of a number $\frac{14-\sqrt{2}}{4}=3.1464466 \ldots$ from Gayatri

method, and its confirmation as $\pi$ value, from Siva method, Jesus proof etc. later, has made the revival of the work of Hippocrates. Hence, this submission of this paper and restoring the golden throne of greatness to Hippocrates has become all the more a bounden duty of this author and the mathematics community.

\section{Squaring of Lunes-(1)}

\section{Procedure}

Hippocrates has squared many types of lunes. In this paper four types of lunes are studied.

"Consider a semi-circle ACB with diameter AB. Let us inscribe in this semi-circle an isosceles triangle $\mathrm{ACB}$, and then draw the circular are $\mathrm{AMB}$ which touches the lines $\mathrm{CA}$ and $\mathrm{CB}$ at $\mathrm{A}$ and $\mathrm{B}$ respectively. The segments ANC, CPB and AMB are similar. Their areas are therefore proportional to the squares of $\mathrm{AC}, \mathrm{CB}$ and 
$\mathrm{AB}$ respectively, and from Pythagora's theorem the greater segment is equivalent to the sum of the other two. Therefore the lune ACBMA is equivalent to the triangle ACB. It can therefore be squared."

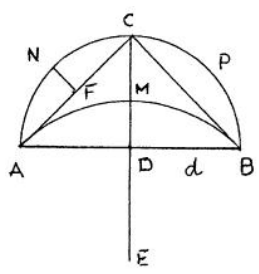

The circular arc AMB which touches the lines $\mathrm{CA}$ and $\mathrm{CB}$ at $\mathrm{A}$ and $\mathrm{B}$ respectively can be drawn by taking $\mathrm{E}$ as the centre and radius equal to $\mathrm{EA}$ or $\mathrm{EB}$.

$\begin{array}{ll}\text { 1. } & \mathrm{AB}=\text { diameter }=\mathrm{d} \\ \text { 2. } & \mathrm{DE}=\mathrm{DC}=\text { radius }=\mathrm{d} / 2 \\ \text { 3. } & \mathrm{F}=\text { midpoint of } \mathrm{AC}\end{array}$

4. $\mathrm{N}=$ midpoint of $\operatorname{arc} \mathrm{AC}$.

5. $\mathrm{NF}=\frac{\sqrt{2} \mathrm{~d}-\mathrm{d}}{2 \sqrt{2}}, \mathrm{DM}=\frac{\sqrt{2} \mathrm{~d}-\mathrm{d}}{2}, \mathrm{MC}=\frac{\sqrt{2} \mathrm{~d}-\mathrm{d}}{\sqrt{2}}$

6. Area of $\mathrm{ANC}=$ Area of $\mathrm{CPB}=\frac{\mathrm{d}^{2}}{16}(\pi-2)$

7. Area of $\mathrm{AMB}=$ Areas of $\mathrm{ANC}+\mathrm{CPB}=\frac{\mathrm{d}^{2}}{8}(\pi-2)$

8. Area of $\mathrm{ACM}=$ Area of $\mathrm{BCM}=\frac{\mathrm{d}^{2}}{16}(4-\pi)$

9. Area of ACB triangle $=\frac{1}{2} \times \frac{\mathrm{d}}{2} \times \mathrm{d}=\frac{\mathrm{d}^{2}}{4}$

10. According to Hippocrates the area of the lune ACBMA is equal to the area of the triangle ACB.

Area of Lune ACBMA = Area of triangle $\mathrm{ACB}$

$(\mathrm{ANC}+\mathrm{CPB}+\mathrm{ACM}+\mathrm{BCM})$

$2\left\{\frac{\mathrm{d}^{2}}{16}(\pi-2)\right\}+2\left\{\frac{\mathrm{d}^{2}}{16}(4-\pi)\right\}=\frac{\mathrm{d}^{2}}{4}$

\section{Squaring of Lunes-(2)}

11. "Let $\mathrm{ABC}$ be an isosceles right angled triangle inscribed in the semicircle ABOC, whose centre is $\mathrm{O}$. $\mathrm{AB}$ and $\mathrm{AC}$ as diameters described semicircles as in figure. Then, since by Ecu. I, 47,

Sq. on $\mathrm{BC}=\mathrm{Sq}$. on $\mathrm{AC}+\mathrm{Sq}$ on $\mathrm{AB}$.

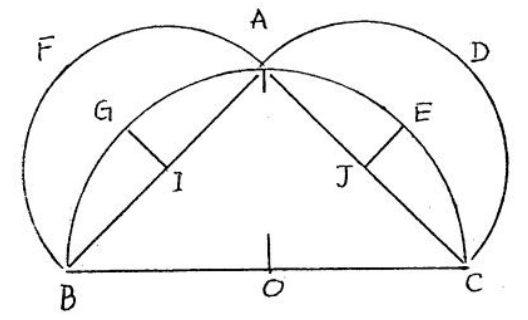

On

Therefore, by Euc. XII, 2,

Area semicircle on $\mathrm{BC}=$ Area semicircle on $\mathrm{AC}+$ Area semicircle on $\mathrm{AB}$.

Take away the common parts

$\therefore$ Area triangle $\mathrm{ABC}=$ Sum of areas of lunes AECD and AFBG.

Hence the area of the lune AECD is equal to half that of the triangle ABC".

12. $\mathrm{BC}=$ diameter $=\mathrm{d}$,

13. $\mathrm{OB}=\mathrm{OC}=$ radius $=\mathrm{d} / 2$

14. $\mathrm{AB}=\mathrm{AC}=\frac{\sqrt{2} \mathrm{~d}}{2}=$ diameter of the semicircle $\mathrm{ABF}=\mathrm{ACD}$

15. $\mathrm{GI}=\mathrm{EJ}=\frac{2 \mathrm{~d}-\sqrt{2} \mathrm{~d}}{4}$

16. Sq. on $\mathrm{BC}=\mathrm{Sq}$. on $\mathrm{AC}+\mathrm{Sq}$. on $\mathrm{AB}$

17. Area of the larger semicircle $=\mathrm{BAC}=\frac{\pi \mathrm{d}^{2}}{8}$

18. Area of the smaller semicircle $=\mathrm{ABF}=\mathrm{ACD}$

Diameter $=\frac{\sqrt{2} \mathrm{~d}}{2}$ 
Area $=\frac{\pi \mathrm{d}^{2}}{8}=\frac{\pi\left(\frac{\sqrt{2} \mathrm{~d}}{2}\right)^{2}}{8}=\frac{\pi \mathrm{d}^{2}}{16}$

18. a) Areas of two smaller semicircles $=2 \times \frac{\pi \mathrm{d}^{2}}{16}=\frac{\pi \mathrm{d}^{2}}{8}$

19. Area of the triangle $\mathrm{ABC}=\frac{1}{2} \times$ base $\times$ altitude

Base $=\mathrm{BC}=\mathrm{d}$, Altitude $=\mathrm{OA}=\frac{\mathrm{d}}{2}$

Area $=\frac{1}{2} \times \mathrm{d} \times \frac{\mathrm{d}}{2}=\frac{\mathrm{d}^{2}}{4}$

20. Segment $\mathrm{AIBG}=$ Segment $\mathrm{AJCE}$

Areas of AIBG + AJCE $=\frac{d^{2}}{16}(\pi-2)+\frac{d^{2}}{16}(\pi-2)=\frac{d^{2}}{8}(\pi-2)$

21. Lune $\mathrm{AGBF}=$ lune $\mathrm{AECD}$

22. Area of the lune (AGBF or AECD)

$=$ Semicircles $(\mathrm{ABF} \& \mathrm{ACD})-$ Segments $(\mathrm{AIBG} \& \mathrm{AJCE})$

$\left(\frac{\pi}{8}\right) \mathrm{d}^{2}-\left(\frac{\pi-2}{8}\right) \mathrm{d}^{2}=\frac{\mathrm{d}^{2}}{4}$

\section{Squaring of lunes-(3)}

"There are also some famous moonshaped figures. The best known of these are the crescents (or lunulae) of Hippocrates. By the theorem of Thales the triangle $\mathrm{ABC}$ in the first figure is right angled: Thus $\mathrm{p}^{2}=\mathrm{m}^{2}+\mathrm{n}^{2}$. The semicircle on $\mathrm{AB}=\mathrm{p}$ has the area

$\mathrm{A}_{\mathrm{AB}}=\pi \mathrm{p}^{2} / 8$; the sum of the areas of the semicircles on $\mathrm{AC}$ and $\mathrm{BC}$ is $\quad \mathrm{A}_{\mathrm{AC}}+\mathrm{A}_{\mathrm{BC}}=\pi\left(\mathrm{n}^{2}+\mathrm{m}^{2}\right) / 8$ and is thus equal to $\mathrm{A}_{\mathrm{AB}}$. From this it follows that:

The sum of the areas of the two crescents is the area of the triangle."

23. $\mathrm{AB}=$ diameter $=\mathrm{d}$

24. $\quad B C=$ radius $=d / 2$

25. $\mathrm{AC}=\frac{\sqrt{3} \mathrm{~d}}{2}$

26. $\mathrm{DF}=\mathrm{d} / 4$

27. $\mathrm{DE}=\frac{2 \mathrm{~d}-\sqrt{3} \mathrm{~d}}{4}$

28. $\mathrm{EF}=\frac{\sqrt{3} \mathrm{~d}-\mathrm{d}}{4}$

29. $\mathrm{GH}=\mathrm{d} / 4$

30. $\mathrm{GJ}=\frac{\sqrt{3} \mathrm{~d}}{4}$

31. $\mathrm{HJ}=\mathrm{GJ}-\mathrm{GH}=\frac{\sqrt{3} \mathrm{~d}}{4}-\frac{\mathrm{d}}{4}=\frac{\sqrt{3} \mathrm{~d}-\mathrm{d}}{4}$

32. Area of the semicircle BDCF

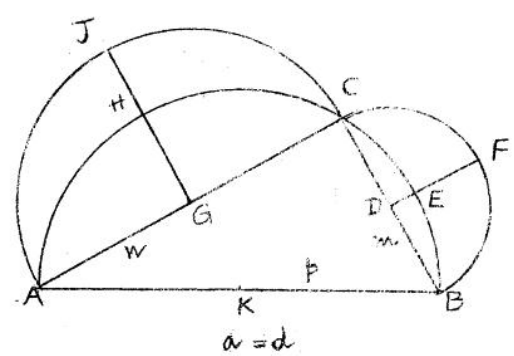

$=\pi \times \frac{\mathrm{d}}{2} \times \frac{\mathrm{d}}{2} \times \frac{1}{8}=\left(\frac{\pi}{32}\right) \mathrm{d}^{2}$

where $\mathrm{BC}=$ diameter $=\frac{\mathrm{d}}{2}$

33. Area of the semicircle AGCJ

$=\pi \times \frac{\sqrt{3} \mathrm{~d}}{2} \times \frac{\sqrt{3} \mathrm{~d}}{2} \times \frac{1}{8}=\left(\frac{3 \pi}{32}\right) \mathrm{d}^{2}$

where $\mathrm{AC}=$ diameter $=\frac{\sqrt{3} \mathrm{~d}}{2}$ 
34. Area of the triangle $\mathrm{ABC}=\frac{1}{2} \times \mathrm{AC} \times \mathrm{BC}=\frac{1}{2} \frac{\sqrt{3} \mathrm{~d}}{2} \times \frac{\mathrm{d}}{2}=\left(\frac{\sqrt{3}}{8}\right) \mathrm{d}^{2}$

35. Area of the curvature entity BDCE $=\left(\frac{2 \pi-3 \sqrt{3}}{48}\right) \mathrm{d}^{2}$

36. Area of the curvature entity AGCH $=($ Circle - AGCH $) \frac{1}{3}$

$\left\{\frac{\pi \mathrm{d}^{2}}{4}-\left(\frac{3 \sqrt{3}}{16}\right) \mathrm{d}^{2}\right\} \frac{1}{3}=\left(\frac{4 \pi-3 \sqrt{3}}{48}\right) \mathrm{d}^{2}$

Area of the triangle $=\left(\frac{3 \sqrt{3}}{16}\right) \mathrm{d}^{2}$, where side $=\mathrm{AC}=\left(\frac{\sqrt{3}}{2}\right) \mathrm{d}$

37. Area of the lune $\mathrm{BECF}=$

Semicircle BDCF - BDCE segment $=\left(\frac{\pi}{32}\right) d^{2}-\left(\frac{2 \pi-3 \sqrt{3}}{48}\right) d^{2}=\left(\frac{6 \sqrt{3}-\pi}{96}\right) d^{2}$

(S.No. 32)

(S.No. 35)

38. Area of the lune AHCJ

Semicircle AGCJ - AGCH segment $=\left(\frac{3 \pi}{32}\right) \mathrm{d}^{2}-\left(\frac{4 \pi-3 \sqrt{3}}{48}\right) \mathrm{d}^{2}=\left(\frac{\pi+6 \sqrt{3}}{96}\right) \mathrm{d}^{2}$

(S.No. 33)

(S.No. 36)

39. Sum of the areas of two lunes = area of the triangle

(S.No. 37) + (S.No. 38)
$=\left(\frac{6 \sqrt{3}-\pi}{96}\right) \mathrm{d}^{2}+\left(\frac{\pi+6 \sqrt{3}}{96}\right) \mathrm{d}^{2}=\left(\frac{\sqrt{3}}{8}\right) \mathrm{d}^{2}$

Squaring of lunes - (4)

The sum of the areas of the lunes is eqal to the area of the square.

40. $\quad \mathrm{AB}=$ side $=\mathrm{d}$

41. $\mathrm{DE}=\mathrm{EC}=\mathrm{d} / 2$

42. $\mathrm{AO}=\mathrm{OC}=\frac{\sqrt{2} \mathrm{~d}}{2}$

43. $\mathrm{EF}=\frac{\sqrt{2} \mathrm{~d}-\mathrm{d}}{2}$

44. $\mathrm{FG}=\frac{\sqrt{2} \mathrm{~d}-\mathrm{d}}{\sqrt{2}}$

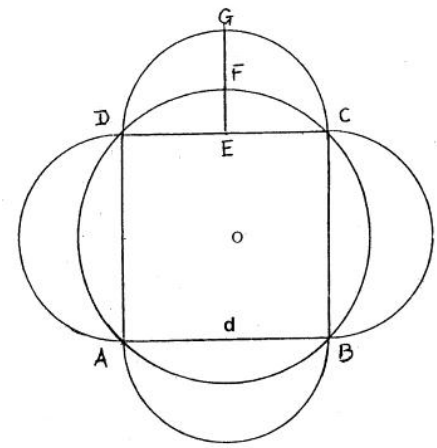

45. Area of the circle $=\frac{\pi \mathrm{d}^{2}}{4}$

Where diameter $=\sqrt{2} \mathrm{~d}$

$\pi \times \sqrt{2} \mathrm{~d} \times \sqrt{2} \mathrm{~d} \times \frac{1}{4}=\frac{\pi \mathrm{d}^{2}}{2}=\left(\frac{\pi}{2}\right) \mathrm{d}^{2}$

46. Area of the semicircle DECG

Where $\mathrm{DC}=$ diameter $=\mathrm{d}=\frac{\pi \mathrm{d}^{2}}{8}=\left(\frac{\pi}{8}\right) \mathrm{d}^{2}$

47. Area of the curvature entity DECF $=\left(\frac{\pi-2}{8}\right) \mathrm{d}^{2}$

48. Area of the lune DFCG

Semicircle DECG - Curvature entity DECF $=\left(\frac{\pi}{8}\right) \mathrm{d}^{2}-\left(\frac{\pi-2}{8}\right) \mathrm{d}^{2}=\frac{\mathrm{d}^{2}}{4}$

49. The sum of the areas of 4 lunes $=$ the area of the square 


$$
4\left\{\left(\frac{\pi}{8}\right) \mathrm{d}^{2}-\left(\frac{\pi-2}{8}\right) \mathrm{d}^{2}\right\}=\mathrm{d}^{2}
$$

\section{Squaring of a semicircle}

"Hippocrates next inscribed half a regular hexagon $\mathrm{ABCD}$ in a semicircle whose centre was $\mathrm{O}$, and on $\mathrm{OA}, \mathrm{AB}, \mathrm{BC}$, and $\mathrm{CD}$ as diameters described semicircles. The $\mathrm{AD}$ is double any of the lines $\mathrm{OA}, \mathrm{AB}, \mathrm{BC}$ and $\mathrm{CD}$,

$\therefore$ Sq. on $\mathrm{AD}=$ Sum of sqs. On $\mathrm{OA}, \mathrm{AB}, \mathrm{BC}$ and $\mathrm{CD}$,

$\therefore$ Area semicircle $\mathrm{ABCD}=$ sum of areas of semicircles on $\mathrm{OA}$, $\mathrm{AB}, \mathrm{BC}$ and $\mathrm{CD}$.

\section{Take away the common parts.}

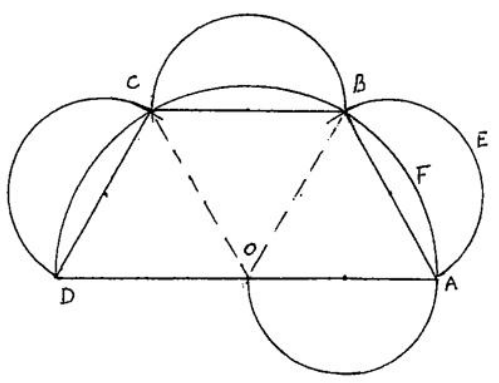

$\therefore$ Area trapezium $\mathrm{ABCD}=3$ lune $\mathrm{AEFB}+$ Semicircle on OA".

\section{0. $\mathrm{DA}=$ diameter $=\mathrm{d}$}

51. Area of the semicircle DABC $=\frac{\pi \mathrm{d}^{2}}{8}=\left(\frac{\pi}{8}\right) \mathrm{d}^{2}$

52. $\frac{\mathrm{DA}}{2}=$ radius of larger semi circle $=\frac{\mathrm{d}}{2}=\mathrm{AB}$

53. $\mathrm{AB}=\frac{\mathrm{d}}{2}=$ diameter of smaller semi circle $\mathrm{ABE}$

$$
\frac{\pi \mathrm{d}^{2}}{8}=\pi \times \frac{\mathrm{d}}{2} \times \frac{\mathrm{d}}{2} \times \frac{1}{8}=\left(\frac{\pi}{32}\right) \mathrm{d}^{2}
$$

54. Areas of semicircle on $\mathrm{OA}, \mathrm{AB}, \mathrm{BC}$ and $\mathrm{CD}=\left(\frac{\pi}{32}\right) \mathrm{d}^{2}$

55. Area of sector OAFB $=\left(\frac{\pi \mathrm{d}^{2}}{4}\right) \frac{1}{6}=\left(\frac{\pi}{24}\right) \mathrm{d}^{2}$

56. Area of the triangle $\mathrm{OAB}=\left(\frac{\sqrt{3}}{16}\right) \mathrm{d}^{2}$

57. Area of the segment AFB $=$ Sector - Triangle

$$
\left(\frac{\pi}{24}\right) d^{2}-\left(\frac{\sqrt{3}}{16}\right) d^{2}=\left(\frac{2 \pi-3 \sqrt{3}}{48}\right) d^{2}
$$

58. Area of lune $\mathrm{AEBF}=$ Semicircle on $\mathrm{AB}-\mathrm{AFB}$ segment

$$
=\left(\frac{\pi}{32}\right) \mathrm{d}^{2}-\left(\frac{2 \pi-3 \sqrt{3}}{48}\right) \mathrm{d}^{2}=\left\{\frac{(6 \sqrt{3}+3 \pi)-4 \pi}{96}\right\} \mathrm{d}^{2}=\mathrm{x}
$$

Area of one lune $=\mathrm{x}$

59. Area of 3 lunes $=3\left\{\frac{(6 \sqrt{3}+3 \pi)-4 \pi}{96}\right\} d^{2}=\left\{\frac{(6 \sqrt{3}+3 \pi)-4 \pi}{32}\right\} d^{2}$

60. Area of 3 lunes + semicircle on OA

$$
=\left\{\frac{\{(6 \sqrt{3}+3 \pi)-4 \pi\}}{32}\right\} d^{2}+\left(\frac{\pi}{32}\right) d^{2}=\left\{\frac{\{(6 \sqrt{3}+3 \pi)-4 \pi\}+\pi}{32}\right\} d^{2}=\left(\frac{6 \sqrt{3}}{32}\right) d^{2}=\left(\frac{3 \sqrt{3}}{16}\right) d^{2}
$$

61. Area of trapezium $=3 \times$ OA triangle

$$
\text { (S.No. 56) }
$$

$$
=3 \times\left(\frac{\sqrt{3}}{16}\right) d^{2}=\left(\frac{3 \sqrt{3}}{16}\right) d^{2}
$$

62. Area of 3 lunes + semicircle on $\mathrm{OA}=$ Area of trapezium $=\left(\frac{3 \sqrt{3}}{16}\right) \mathrm{d}^{2}=\left(\frac{3 \sqrt{3}}{16}\right) \mathrm{d}^{2}$

(S.No. 60) 


\section{Squaring of circle}

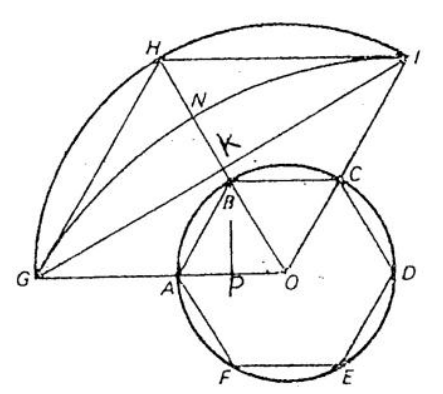

"Consider two concentric circles with common centre $\mathrm{O}$ and radii such that the square of the radius of the larger circle is six times the square of the radius of the smaller one. Let us inscribe in the smaller circle the regular hexagon $\mathrm{ABCDEF}$. Let $\mathrm{OA}$ cut the larger circle in $\mathrm{G}$, the line $\mathrm{OB}$ in $\mathrm{H}$ and the line $\mathrm{OC}$ in I. On the line GI we construct a circular segment GNI similar to the segment GH. Hippocrates shows that the lune GHIN plus the smaller circle is equivalent to the triangle GHI plus the hexagon."

63. $\mathrm{OA}=$ radius of the smaller circle $=\frac{\mathrm{d}}{2}$
64. $\mathrm{OH}=$ radius of the larger circle $=\sqrt{6\left(\frac{\mathrm{d}}{2}\right)^{2}}=\left(\frac{\sqrt{6}}{2}\right) \mathrm{d}$

65. Third circle: $\mathrm{GI}=$ radius $=\mathrm{GK}+\mathrm{KI}$

66. $\mathrm{OH}=\mathrm{OI}=\left(\frac{\sqrt{6}}{2}\right) \mathrm{d}$

67. $\mathrm{OK}=\frac{\mathrm{OH}}{2}=\left(\frac{\sqrt{6}}{4}\right) \mathrm{d}$

68. $\mathrm{KI}=\sqrt{(\mathrm{OI})^{2}-(\mathrm{OK})^{2}}=\left(\frac{3 \sqrt{2}}{4}\right) \mathrm{d}$

69. Radius of the third circle

$=\mathrm{GI}=2 \times \mathrm{KI}=\left(\frac{3 \sqrt{2}}{2}\right) \mathrm{d}$

70. Area of the GHI triangle $=\frac{1}{2} \times \mathrm{GI} \times \mathrm{HK}$

$\mathrm{HK}=\frac{\mathrm{OH}}{2}=\left(\frac{\sqrt{6}}{4}\right) \mathrm{d}$

$=\frac{1}{2} \times\left(\frac{3 \sqrt{2}}{2}\right) \mathrm{d} \times\left(\frac{\sqrt{6}}{4}\right) \mathrm{d}=\left(\frac{3 \sqrt{3}}{8}\right) \mathrm{d}^{2}$

71. Area of the AOB triangle

$\mathrm{OA}=\mathrm{AB}=\frac{\mathrm{d}}{2} ; \quad \mathrm{AP}=\frac{\mathrm{OA}}{2}=\frac{\mathrm{d}}{4}$

$\mathrm{PB}=\sqrt{(\mathrm{AB})^{2}-(\mathrm{AP})^{2}}=\left(\frac{\sqrt{3}}{4}\right) \mathrm{d}$;

Area $=\frac{1}{2} \times \mathrm{OA} \times \mathrm{PB}=\frac{1}{2} \times \frac{\mathrm{d}}{2} \times\left(\frac{\sqrt{3}}{4}\right) \mathrm{d}=\left(\frac{\sqrt{3}}{16}\right) \mathrm{d}^{2}$

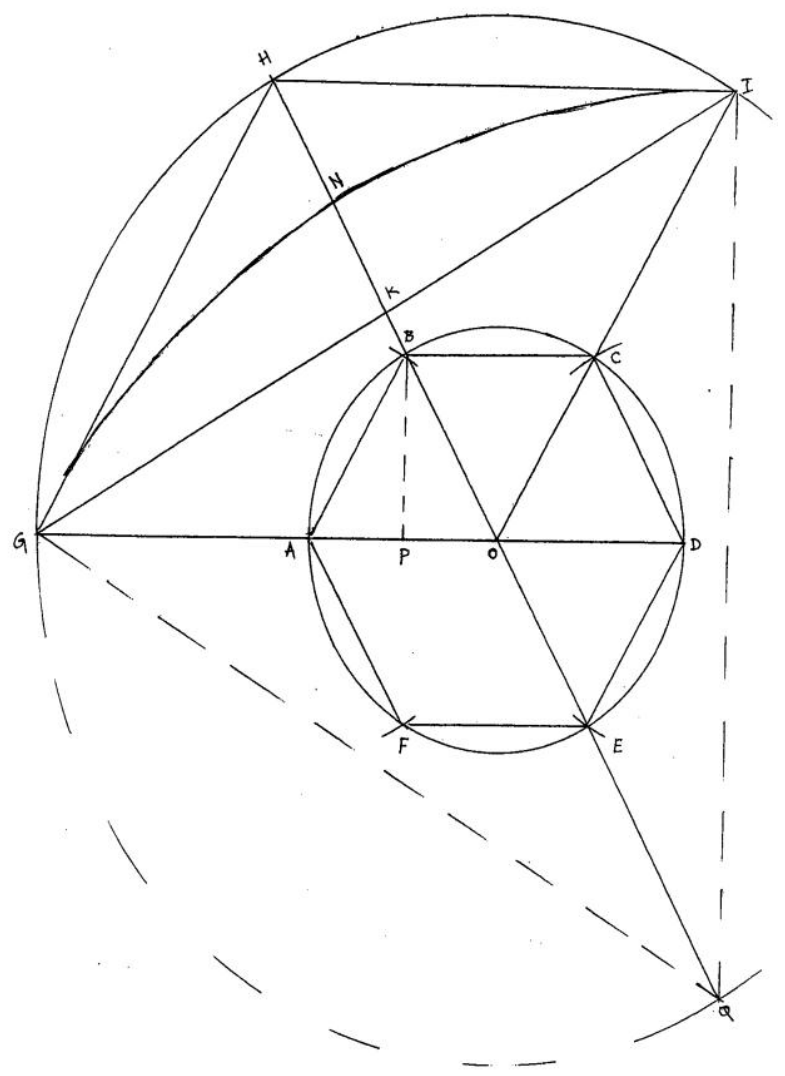

72. Area of the hexagon $=$ Area of the triangle AOB $\times 6$

$=\left(\frac{\sqrt{3}}{16}\right) \mathrm{d}^{2} \times 6=\left(\frac{6 \sqrt{3}}{16}\right) \mathrm{d}^{2}=\left(\frac{3 \sqrt{3}}{8}\right) \mathrm{d}^{2}$

73. Area of the smaller circle $=\frac{\pi \mathrm{d}^{2}}{4}=\left(\frac{\pi}{4}\right) \mathrm{d}^{2}$

74. Area of the segment $\mathrm{GH}=$ Segment HI

75. Area of the larger circle $=\frac{\pi \mathrm{d}^{2}}{4}$

Where $d=\left(\frac{\sqrt{6}}{2}\right) d \times 2=\sqrt{6} d=\pi \times \sqrt{6} d \times \sqrt{6} d \times \frac{1}{4}=\left(\frac{6 \pi}{4}\right) d^{2}$

76. Area of the larger circle is divided into 6 sectors $=\left(\frac{6 \pi}{4}\right) \mathrm{d}^{2} \times \frac{1}{6}=\left(\frac{\pi}{4}\right) \mathrm{d}^{2}$ 
77. Area of the triangle $\mathrm{OGH}=\mathrm{OHI}=\mathrm{GHI}=\left(\frac{3 \sqrt{3}}{8}\right) \mathrm{d}^{2}$

(S.No. 70)

78. $\quad$ Area of the $\mathrm{GH}$ segment $=\mathrm{HI}$ segment

$=$ Sector - Triangle $(\mathrm{OGH})=\left(\frac{\pi}{4}\right) \mathrm{d}^{2}-\left(\frac{3 \sqrt{3}}{8}\right) \mathrm{d}^{2}=\left(\frac{\pi}{4}-\frac{3 \sqrt{3}}{8}\right) \mathrm{d}^{2}$

(S.No. 76) (S.No. 77)

There are two segments GH and HI $=2\left(\frac{\pi}{4}-\frac{3 \sqrt{3}}{8}\right) \mathrm{d}^{2}=\left(\frac{2 \pi-3 \sqrt{3}}{4}\right) \mathrm{d}^{2}$

79. Similarly, GNIK is also another segment which is the part of the sector GNIQ. It consists of the triangle GIQ and GNIK segment.

80. To find out the area of the sector GNIQ, let us first find out the area of the circle whose diameter is equal to that of the third circle.

Diameter of the third circle $=$ riadus $\times 2=\left(\frac{3 \sqrt{2}}{2}\right) \mathrm{d} \times 2=(3 \sqrt{2}) \mathrm{d}$

(S.No. 69)

Area $=\frac{\pi \mathrm{d}^{2}}{4}=\pi \times(3 \sqrt{2}) \mathrm{d} \times(3 \sqrt{2} \mathrm{~d}) \times \frac{1}{4}=\left(\pi \times 18 \times \frac{1}{4}\right) \mathrm{d}^{2}=\left(\frac{9 \pi}{2}\right) \mathrm{d}^{2}$

81. Then let us find out the area of the sector $=\left(\frac{1}{6} \mathrm{th}\right)=\left\{\left(\frac{9 \pi}{2}\right) \mathrm{d}^{2}\right\} \frac{1}{6}=\left(\frac{9 \pi}{12}\right) \mathrm{d}^{2}=\left(\frac{3 \pi}{4}\right) \mathrm{d}^{2}$

82. Now let us find out the area of the triangle GIQ $=\frac{1}{2} \times \mathrm{GI} \times \mathrm{KQ}$

Where $\mathrm{KI}=\frac{\mathrm{GI}}{2}=\left(\frac{3 \sqrt{2}}{2}\right) \mathrm{d} \times \frac{1}{2}=\left(\frac{3 \sqrt{2}}{4}\right) \mathrm{d}$

$\mathrm{GI}=\mathrm{QI}=\mathrm{GQ}=$ Radius of the third circle.

$\mathrm{KQ}=\sqrt{(\mathrm{QI})^{2}-(\mathrm{KI})^{2}}=\sqrt{\left\{\left(\frac{3 \sqrt{2}}{2}\right) \mathrm{d}\right\}^{2}-\left\{\left(\frac{3 \sqrt{2}}{4}\right) \mathrm{d}\right\}^{2}}=\left(\frac{3 \sqrt{6}}{4}\right) \mathrm{d}$

Area $=\frac{1}{2} \times \mathrm{GI} \times \mathrm{KQ}=\frac{1}{2} \times\left(\frac{3 \sqrt{2}}{2}\right) \mathrm{d} \times\left(\frac{3 \sqrt{6}}{4}\right) \mathrm{d}=\left(\frac{9 \sqrt{3}}{8}\right) \mathrm{d}^{2}$

83. Area of the segment GNIK $=$ Sector - Triangle

(S.No. 81)

$=\left(\frac{3 \pi}{4}\right) \mathrm{d}^{2}-\left(\frac{9 \sqrt{3}}{8}\right) \mathrm{d}^{2}=\left(\frac{6 \pi-9 \sqrt{3}}{8}\right) \mathrm{d}^{2}$

(S.No. 82)

84. Now it has become possible to calculate the area of GHIN segment

$=$ Triangle GHI - Segment GNIK

(S.No. 70) (S.No. 83)

$=\left(\frac{3 \sqrt{3}}{8}\right) \mathrm{d}^{2}-\left(\frac{6 \pi-9 \sqrt{3}}{8}\right) \mathrm{d}^{2}=\left(\frac{6 \sqrt{3}-3 \pi}{4}\right) \mathrm{d}^{2}$

Area $=\left(\frac{6 \sqrt{3}-3 \pi}{4}\right) \mathrm{d}^{2}$

85. Area of the lune GHIN

Segments + Segments + Circle $=$

GH \& HI GHIN

S.No. $78 \quad$ S.No. 84 S.No. 73

$=\left(\frac{2 \pi-3 \sqrt{3}}{4}\right) \mathrm{d}^{2}+\left(\frac{6 \sqrt{3}-3 \pi}{4}\right) \mathrm{d}^{2}+\left(\frac{\pi}{4}\right) \mathrm{d}^{2}=\left(\frac{3 \sqrt{3}}{4}\right) \mathrm{d}^{2}$

86. Area of the triangle GHI + Area of the hexagon ABCDEF

(S.No. 70)

(S.No. 72) 


$$
\left(\frac{3 \sqrt{3}}{8}\right) \mathrm{d}^{2}+\left(\frac{3 \sqrt{3}}{8}\right) \mathrm{d}^{2}=\left(\frac{3 \sqrt{3}}{4}\right) \mathrm{d}^{2}
$$

87. Area of lune + Circle $=\left(\frac{3 \sqrt{3}}{4}\right) \mathrm{d}^{2}=$ Area of triangle + hexagon $=\left(\frac{3 \sqrt{3}}{4}\right) \mathrm{d}^{2}$

(S.No. 85)

(S.No. 86)

So, the sum of the areas of lune and circle is equal to the sum of the areas of triangle and hexagon.

\section{Post Script}

The following are the points on which some thinking is necessary:

1. $\quad 3.14159265358 \ldots$ is accepted as $\pi$ value.

2. $3.14159265358 \ldots$ is a transcendental number.

3. As this polygon's value is accepted as $\pi$ of the circle, circle and its $\pi$ value have become transcendental entities.

4. The concept of transcendental number vehemently opposes squaring of circle.

\section{Latest developments}

5. $\frac{14-\sqrt{2}}{4}=3.14644660942 \ldots$ is the new $\pi$ value.

6. $\frac{14-\sqrt{2}}{4}$ is the exact value.

7. This number is an algebraic number, being the root of $x^{2}-56 x+97=0$

8. Squaring of circle is done with this number.

\section{Conclusion}

9. Hippocrates did square the circle.

10. $3.14159265358 \ldots$ is a transcendental number - it is correct.

11. $3.14159265358 \ldots$ can not square a circle, - is also correct.

\section{Final verdict}

12. As Hippocrates did the squaring a circle, it amounts to confirming that circle and its $\pi$ value are algebraic entities. It implies that as $3.14159265358 \ldots$ is a borrowed number from polygon and attributed to circle, called a transcendental number, said squaring a circle an unsolved geometrical problem, the final verdict is, all are correct, except one, i.e. attributing 3.14159265358 of polygon to circle. Hence $3.14159265358 \ldots$ is not a $\pi$ value at all.

\section{References}

[1]. T. Dantzig (1955), The Bequest of the Greeks, George Allen \& Unwin Ltd., London

[2]. P. Dedron and J. Itard (1973) Mathematics and Mathematicians, Vol.2, translated from French, by J.V. Field, The Open University Press, England.

[3]. W.W. Rouse Ball (1960), A short Account of the History of Mathematics, Dover Publications, New York.

[4]. W.G.H. Kustner and M.H.H. Kastner (1975). The VNR Concise Encyclopedia of Mathematics, Van Nostrand Rusinhold Company.

[5]. R.D. Sarva Jagannadha Reddy (2014). Pi of the Circle at www.rsjreddy.webnode.com 